\title{
Fusing the Jigsaw Method and Microsoft Teams: A Promising Online Pedagogy
}

\author{
Malissa Maria Mahmud \\ Sunway University, Selangor, Malaysia \\ https://orcid.org/0000-0001-6702-155X \\ Shiau Foong Wong \\ Sunway University, Selangor, Malaysia \\ https://orcid.org/0000-0002-3252-8163
}

\begin{abstract}
The Covid-19 pandemic has triggered a universal disruption over the past year, and has caused unforeseen and formidable changes, but simultaneously has also enthused a digital transformation for educational institutions of all levels. With the upsurge in the usage of digital technologies, some potential caveats should be addressed, in particular, the speculative effective methods, course design and structure. A prodigious deal of reappraising and reimagining the philosophy of what is deemed to be the most familiar is imperative, not only to promote student-centred learning, but also encourage online engagement. Considering the suspension of all face-to-face classes due to the rapid spread of the global pandemic, the purpose of this study was to assess the usability and adoption of the jigsaw method on the web-based platform, Microsoft (MS) Teams for both synchronous and asynchronous teaching and learning. A pre-experimental research design was utilised with one post-test dataset obtained from the post-experiment learning analytics. Subsequently, the usability and adoption of the jigsaw method in MS Teams were evaluated based on the reciprocity of students' responses towards the design. It is postulated that MS Teams stand out as a promising technological tool to facilitate the integration of the jigsaw method into an online learning environment. It advocates better students engagement and collaboration, and thus leads to the positive impact on students' performance and enhanced comprehension of course content, specifically the availability of customized MS Teams features; channel and synchronous chat, which are recommended to support an engaged learning ecology.
\end{abstract}

Keywords: online pedagogy; educational technology; jigsaw method; MS Teams; engagement 


\section{Introduction}

Technology is ubiquitous and transformations are inevitable. Various sectors and institutions have witnessed a myriad of revolutions due to technology. Educational institutions, for instance, have experienced and adapted to the changing pedagogical modalities which modes of delivery are designed to facilitate the current needs. The buzzwords such as 'online learning' or 'blended learning' are not new. The ideology of integrating technological tools in the teaching and learning setting started way back in the 1980s, and with the arrival of Internet, emerging technological apparatuses became more feasible, and are employed and leveraged to facilitate both asynchronous as well as synchronous approaches. In their study, Dziuban and colleagues (2016) expounded four stages of how online education evolved over the years, primarily in America: the first stage, which occurred in the 1990s, was when the Internet incited distance education. Stage 2, from year 2000 to 2007, saw the increased use of Learning Management Systems (LMS). Next, stage 3 ensued from 2008 to 2012 in which the education sector experienced and witnessed the development of Massive Open Online Courses (MOOCs), and stage 4 ascertained that the advancement of technology has surpassed beyond the traditional pedagogic methods. These four stages offer a lens through which the tremendous and incremental changes in educational technology can be studied. The digitally-rich environment has proffered depth and breadth of opportunity for educational change (Mahmud et al., 2020). While the effectiveness of technology incorporation has been the key issue, new technologies often times necessitate reconceptualization of teaching and learning, for instance, the development of a digital environment that could successfully engage students online. Students' engagement is synonymous with face-to-face approaches, and are known to be more effective as opposed to online modalities. Czerkawski and Lyman (2016, p. 538) suggested that "research on student engagement is yielding increasingly complex questions and issues, the need for research exploring engagement in the context of online learning is greater than ever".

Conventional student-centred approaches such as the jigsaw method is one of the go-to activities for many teachers. This is practically when the role of the teacher is eliminated from the equation, while students are highly engaged and take ownership of both their classmates' learning as well as their own. Despite being one of the common methods, not all teachers are familiar with the implementation or application of jigsaw online. The jigsaw method is a pedagogical approach that has the potential to be the catalyst of interest, and can spark interaction through discussion and/or collaboration. But the question lies in the daunting task to align technology tools with the various pedagogies and design an online environment which can foster and support a sense of engagement in order to translate from the physical or face to face (F2F) to the virtual classroom, even for the most experienced teachers. With the COVID-19 disruption to the traditional face-toface approach, there is a sense of urgency not only to appraise the usability and adoption of the jigsaw method in MS Teams, but also to propose a unified design, combining the familiar aspects of the jigsaw method and tools, function and features on the MS Teams. 


\section{Literature Review}

\subsection{Jigsaw Classroom}

The jigsaw classroom is a common research-based cooperative learning technique invented and developed in the early 1970s by Elliot Aronson and his students at the University of Texas and California (Aronson, 1978). The main aim of developing the jigsaw method in teaching and learning was to improve intergroup relations and peer-to-peer learning (Aronson, 2002). It was also aimed at cultivating race relations among group members through learning (Williams, 2004), convalescing skills in group work (Lazzari, 2014), and learning in diverse groups (Crone \& Portillo, 2013). It is grounded on students' autonomy, competence, and social relatedness (Hänze \& Berger, 2007). It was developed in response to Texas's racial segregation that affected the classroom environment (Aronson, 1978). It aimed at building empathy and compassion in racially diverse peer-learning groups (Aronson, 2002). The jigsaw classroom method was designed to engage the students individually in a group and improve their personal, learning, and thinking skills (Hastie \& Casey, 2010). Nusrath et al. (2019) described the jigsaw classroom approach to learning as an alternative to the conventional classroom learning approach. It includes learning through teaching and sharing in the classroom (Norintan, 2008). Rahmat (2017) views jigsaw classrooms as a fun and interactive approach to classroom activity. The jigsaw classroom approach to learning has been successfully applied in classrooms globally.

The jigsaw classroom can be viewed from the perspectives of the theories on social loafing, social compensation, trait activation, and social-cultural and learnercentred approaches to learning (Wang, 2007) to understand its stress on the importance of interaction between learners in promoting language development. The jigsaw classroom was designed to improve classroom cohesion and accountability; however, it has been faulted for lacking an applicable structure that could improve college students' collaborative learning and promote accountability (Bratt, 2008). Effendi-Hasibuan et al. (2020) highlighted the lack of an education system that supported jigsaw classrooms. Amador and Mederer (2013) blamed the lack of individualized support in the online learning settings on learning institutions' failure to implement jigsaw classrooms in e-learning. The jigsaw classroom approach to cooperative learning effectively combines content and language teaching (Rahmat, 2017), while providing an opportunity for purposeful communication (Casey \& Fernandez-Rio, 2019). Walker and Crogan (1998) noted that applying a jigsaw classroom in learning impacts academic performance, self-esteem, school liking, peers' liking, and racial prejudice. According to Ab Murat (2008), the jigsaw classroom enhanced students' ability to understand subject topics and recall class content. Crone and Portillo (2013) proved that the jigsaw classroom helped to improve students' confidence and oral communication abilities, and Sopyan et al. (2019) pointed out the significant impact of the jigsaw classroom on students' reading skills. 


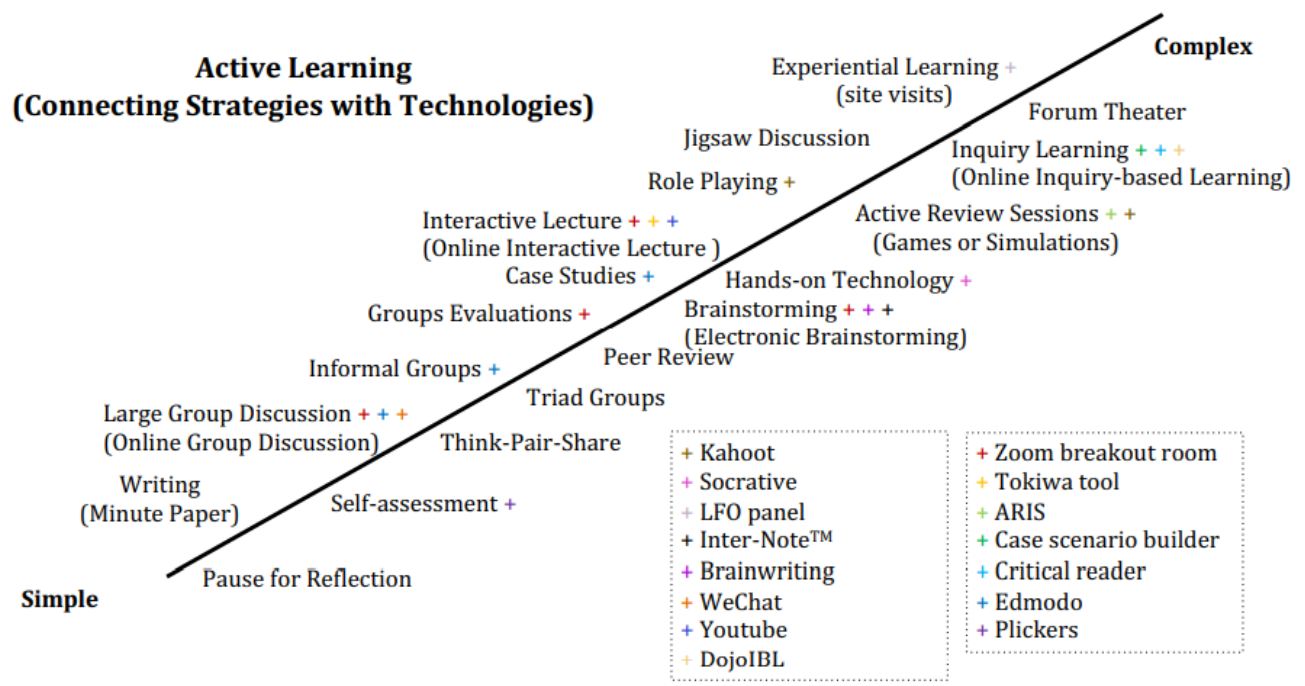

Figure 1: Active Learning Strategies Alongside Learning Technologies

Figure 1 illustrates the findings of active learning strategies alongside valuable learning technologies. At this juncture, the range of selected active learning is aligned and arranged based on the level of difficulty and time required, and was put together by Chris O'Neal and Tershia Pinder Grover of the Centre for Research on Learning and Teaching, University of Michigan (Hasnine et al., 2020). Here, it can be observed that the jigsaw method is included as an active learning strategy, specifically beneficial in augmenting higher order thinking skills. In a similar vein, creative skills were found to be improved, correlating with the students' performance (Rahimi \& Yadollahi, 2017). The current learning environment is filled with different technologies. In this era of information overload, teachers play a role in shaping students' systematic learning approach (Nusrath et al., 2019). Although the jigsaw is common for face-to-face delivery, modern jigsaw classrooms use different technologies and digital platforms to support learning. Online jigsaw classrooms aim to improve the efficiency of collaborative learning. Balestrini et al. (2014) believe that technology-supported jigsaw classrooms are better than paper-based jigsaw classrooms as significantly less time is spent on activity organization, idea sharing, and class content awareness. The efficiency of online jigsaw classrooms can be credited to the efficiency in learning aided by technologies. Technology-supported study groups improved learners' test scores and the overall learning experiences.

The jigsaw method is common for face-to-face delivery. It can be used in two basic ways: as (1) a discussion/ peer-learning experience as an end in itself, and/or (2) a work team that produces a tangible group product or project. In both cases, the jigsaw group arrangement allows students to help each other understand information about corresponding topics by apportioning a different topic, theory, or reading, and sharing their expertise with others in the group. Jigsaw activities which are recommended by Amador and Mederer (2013) are those in which students are organized into several groups to link various topics together. Each student is asked to complete an individual assignment related to the assigned topic. The first step of the jigsaw group exercise involves students analysing their 
assigned topic in two different ways. In the first step, they strengthen their expertise by participating in an "expert group" where they discuss their assigned topic. Jigsaw activities can be differentiated by giving some of the expert groups easier tasks to do or shorter texts to read. The second step in the jigsaw puzzle is when groups are composed of individuals who have identified themselves as experts on a different topic. They then deliberate similarities and differences during the discussion session. If the experience is organized in a group, instructions are given on how to organize the group process. An outline for the project is provided along with a grading rubric. Although the group assignment can be graded or ungraded, it can be used to evaluate understanding and reward group members. This method is most likely to improve learning when used as a reward. Often times, the first step of the jigsaw process can be omitted, however, it is still very beneficial for students to practise contributing effectively to discussions. This step helps build confidence in their ability to participate. One of the most common issues that arise with the face to face (F2F) classroom is the absence of a student. This issue can be solved by having a brief write-up of the topics for the groups and the missing members.

To migrate the energy that encapsulates the F2F class to the online modalities, a sense of community needs to be emphasized, and that students can discuss topics related to their lives in a socially informed way. In addition, the anatomy of F2F course is emulated online through the governance of the facets suggested by the K. Patricia Cross Academy (2020), such as, small class size, student skills level, and the capacity of the learning management system (LMS). Next, the tools to be employed in the activity are to be identified, such as text documents, videos, webpages, a web-based discussion forum and a video conference, equipped with break-out rooms where students can work collaboratively in smaller groups.

\subsection{MS Teams}

MS Teams is part of the Office 365 ecosystem, and predominantly, MS Teams support collaboration and teamwork. It is increasingly employed by numerous organisations and thus has an increasing influence on how collaborative tasks, in particular, are conducted and organised. Its particular features are that it is userfriendly, for example, it uses the 'general' and customized channels, which each contains well-known tabs such as 'post, file, class notebook, assignment and grade'. The consolidation of file storage on SharePoint, where all files can be shared via posts or chats, takes place automatically, thus saving the files of each channel. Another positive feature is that online video calls and screen sharing for synchronous meetings and discussions can be done with the 'share screen' feature to better support teaching activities which can be recorded for post-class reference. The integrated "chat' feature reinforces a sense of collegiality. As such, collaborative communication among team members and teacher can be easily executed.

Numerous web-based platforms offer break-out rooms as one of the features for students and educators to use. Break-out rooms offer opportunities for active online learning in which functions can be designed to encompass jigsaw activities scaffolded by the break-out room feature. This encourages metacognition and reflection and, most importantly, students are more engaged in the lesson (Riggs 
\& Linder, 2016). For example, GoogleMeet, MS Teams, Zoom, Webex and Discord can be used to create jigsaw break-out rooms to conduct online classes with a synchronous delivery mode, while for an asynchronous delivery mode, jigsaw break-out rooms can be created through MS Teams, NowComment and MyBB web-based platforms. The MS Teams break-out rooms can be used in two basic ways. First, it is used as a discussion or peer-learning experience as an end in itself. Second, it can be used to produce a tangible group product or project of a work team. By leveraging on the jigsaw method, MS Teams provides a platform for students to help each other in understanding the content about one particular topic by distributing the learning work. Every student in a small group is responsible for mastering a different topic and sharing his/her expertise with others in the group.

\section{Methodology}

Prior to the COVID-19 pandemic, courses or subjects at the university were mainly taught using the F2F approach. Contact hours primarily were spent on F2F lectures, tutorials, small-group and whole-class discussions. With remote teaching and learning, three strategies such as synchronous, asynchronous and blended learning seem to be the most feasible to facilitate and support online education. For this study, synchronous and asynchronous feedback and interaction were carefully collated and examined, wherein this approach also serves as a preexperimental or feasibility approach before any experimental research was conducted. This design was used to evaluate the usability and adoption of the jigsaw method in MS Teams, measured by the level of engagement. Stanley (1966) identified the experimental design, which affords an extent of experimental control and, in turn, a higher degree of validity.

\subsection{Participants}

The participants were students and academic staff involved in the following courses:

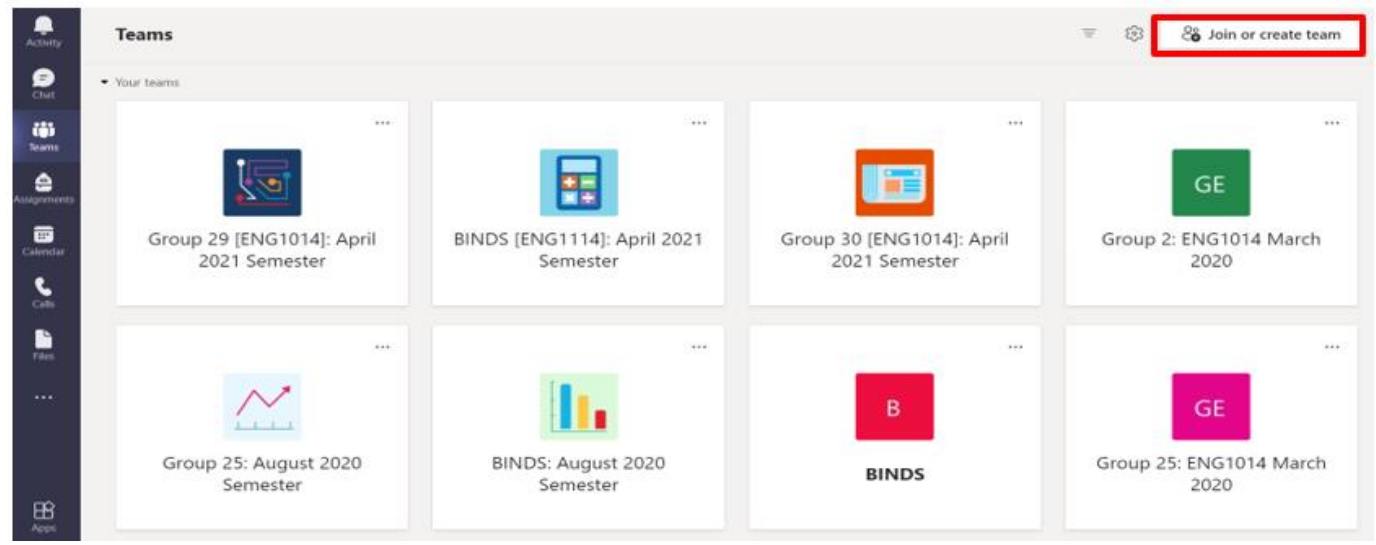

Figure 2: Courses created on MS Teams

The jigsaw activities were employed in the MS Teams break-out rooms and conducted synchronously (real-time), involving two English for Specific Purposes programmes in March and August, 2020 and April, 2021 semesters (see Fig. 2). These courses comprise a four-credit course required for students in the 
undergraduate programmes, for example Accounting, Business, Finance, Marketing, Actuarial, Statistics, Biology, Medicine, Psychology, Computing, Communication and Creative Arts to complete during their first and second year of studies at the university. The duration of the course is 14 weeks, and it usually is offered twice in an academic year. The teachers are full-time academic staff and are the owners of the team created. The team is created by selecting "Join or Create Team" (refer to Fig. 2). Students can join the team or be added as members using a link or a generated "Team Code" provided by the teachers or administrators. As owners of the team, teachers can assign work, such as tutorials, tasks and practices, share class content, upload files, start meetings, and control who may post in the team. Each class team is also connected to its own OneNote Class Notebook. The name and description of the team can be modified to reflect the courses/ class/ level.

\subsection{Jigsaw Method Procedure}

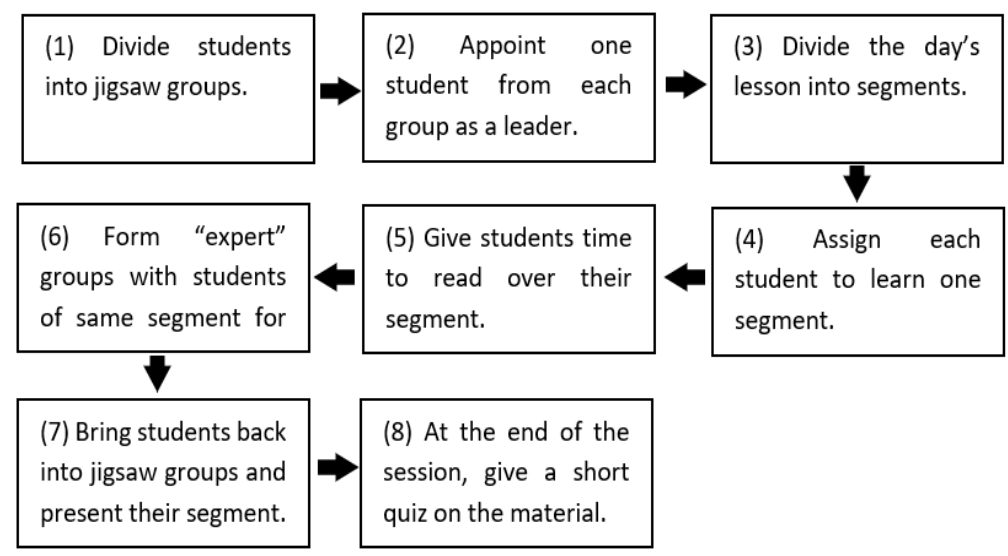

Figure 3: Flow of the adoption of the jigsaw break-out rooms

The jigsaw procedure involved eight easy steps as shown in Figure 3. First, students are divided into jigsaw groups that are diverse in terms of gender, ethnicity, race and ability, which indirectly will build the students' confidence and communication skills. Secondly, one student from each group is appointed as the leader, which initially, should be a mature student. The group leader can be trained to ensure an appropriate intervention and to assist if a member encounters problems. In the third step, the lesson of the day is divided into segments or topics, which must be equal to the number of groups. Then, each student is assigned one segment of the lesson to learn. It is important to ensure students have direct access only to their own segment, and it is distributed via digital platform, or LMS. In step 5, students are given time to read over their segment at least twice to become familiar with the content of the segment. After that, "expert" groups are formed by having one student from each jigsaw group joining other students to whom the same segment or topic was assigned. Time is given for these students in their respective "expert" groups to discuss the main points of their segment and to rehearse the presentations that they will make to their jigsaw group. This is to strengthen each other's understanding in preparation for the jigsaw group later. In step 7, the students are brought back to their initial jigsaw groups, and presentations on their segment is done. Other 
students in the group are advised and encouraged to take notes and ask questions for further clarification and better understanding. Lastly, a short quiz on the material is given at the end of the session to assess the understanding of the students. It is essential that these sessions are not just games and for fun, but scores should be really counted individually so that each score can be averaged to obtain the group's score.

\subsection{Instruments}

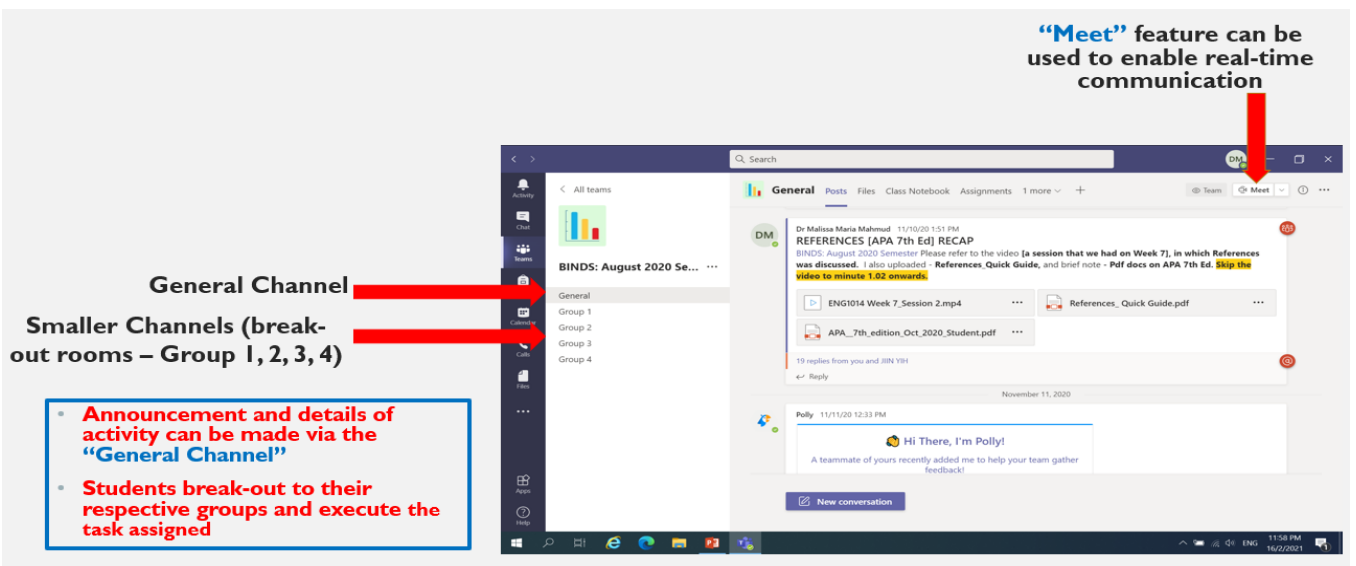

Figure 4: Synchronous and Asynchronous Jigsaw break-out rooms adopted in MS Teams

Figure 4 shows the layout of synchronous and asynchronous jigsaw break-out rooms adopted in MS Teams for one of the classes, BINDS, in the August, 2020 semester. For synchronous mode, both verbal and written communications were conducted via the live session during class time, while for the asynchronous mode, all communication was done via a post created in the respective channels. All the students were included in the "General" channel as the team members. Announcement and details of activities can be made known via the "General" channel to convey messages to all the team members. Likewise, it also functions as a public discussion forum where students and teacher can communicate with each other, either synchronously or asynchronously.

The smaller channels which represent different jigsaw groups and "expert" groups were added to the class, where students "break out" into their respective groups in preparation for the implementation of the jigsaw break-out rooms, including Group 1, 2, 3 and 4 as shown in the figure above. Students of each jigsaw group were assigned to one particular group representing the jigsaw break-out room. In "expert" groups, only students with the same segment or topic met for a discussion to enhance their understanding of the segment of which they were "in charge", and execute the task assigned. Students were brought back to their own jigsaw break-out room to present their individual segment and learn the lesson from each other after they had a discussion in "expert" groups. Private discussion forums can be conducted synchronously or asynchronously in each smaller channel, by posting messages on the channels or through live discussions. For live and real-time communication, the "Meet" feature can be used, and both students and teacher meet virtually so that more focused and independent deliberations can take place. At this juncture, the teacher plays the supporting role to give 
instructions, facilitate learning and group discussions, provide feedback and intervene as necessary in assisting the students to execute the tasks. To execute the jigsaw method in the class, prior planning is important for the lesson which comprises structured and clear instructions that are given to all the students via the "General" channel. For the first class in week 11, on 21 June 2021, which was the experimental session, the details of assigned tasks with the suggested time to spend on each task were provided to students to allow them to start the work in their respective jigsaw break-out rooms: Groups 1, 2, 3 or 4 . Instructions on how and when to submit were also provided to the students. The non-experimental session was conducted in the same week, on 23 June 2021, and similar to the experimental session, instructions were provided to all the students through the "General" channel on which a live class was conducted, using the "Meet" feature. This Time, the jigsaw method was not adopted for the session; instead, the session only consisted of synchronous discussions.

\subsection{Analyses}

The analyses used for this study were divided into two means. The first method of analysis was to probe the usability and adoption of MS Teams, and, in particular, the employment of the jigsaw method in an online modality. At this juncture, both of the synchronous and asynchronous collaborative interaction and feedback on MS Teams were carefully examined to qualify the measurement. The importance of collating the end-user feedback is highlighted in a study conducted by Preece and colleagues (2007), in which methodical data collection was applied to inform the usage of a tool. Similarly, Chilana et al. (2011) asserted that evaluation as an iterative process was used to understand the users' perceptions of and behaviours towards a system. The second mean of analysis comprised a post-test dataset attained from the MS Teams learning analytics in which information on the students' engagement was yielded. Learning analytics has become a common tool to offer informed recommendations and future directions, specifically for learning experiences (Albó et al., 2019; Tsai \& Brusilovsky, 2019). In this context, the dataset directly complemented the students' feedback to add another layer of understanding to the implementation of MS Teams and the jigsaw method.

\section{Findings}

For this study, a pre-experimental research design was employed to evaluate the usability and adoption of MS Teams, measured against the synchronous and asynchronous collaborative interaction and feedback. To fortify the relevance, the analytics of one post-test dataset, attained from the experimental MS Teams' learning session, conducted on 21 June, 2021 was also used to compare the level of engagement for the non-experimental session of 23 June, 2021. 


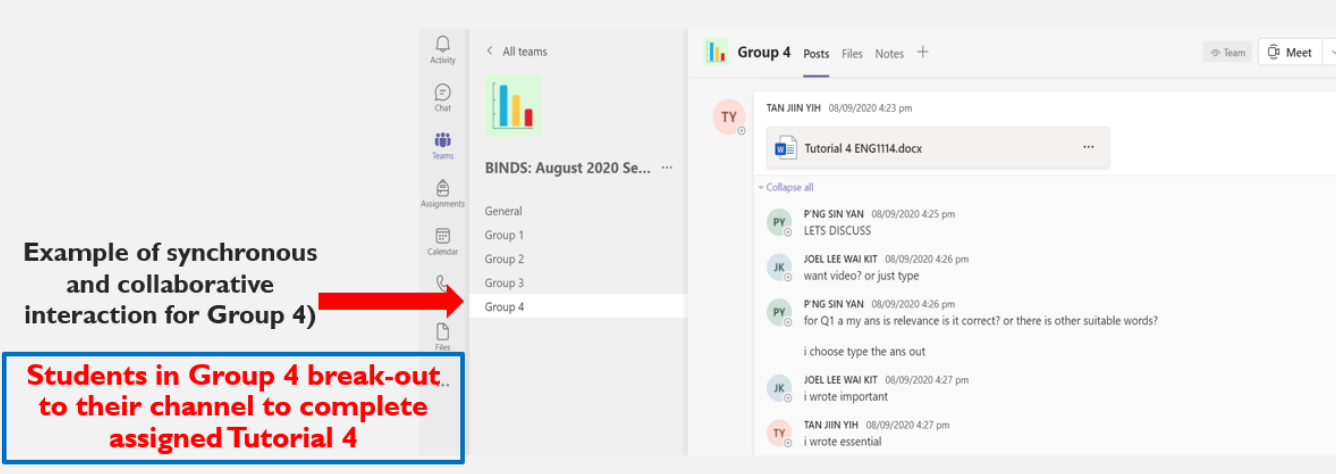

Figure 5: Example of Interaction of Synchronous Jigsaw Break-out Room for Tutorial Completion

Figure 5 shows the example of the synchronous and collaborative interaction for one of the jigsaw break-out rooms, Group 4, to complete the assigned Tutorial 4. It is seen that one of the students shared the details of Tutorial 4 through Group 4 , which was the smaller channel representing the jigsaw break-out room. It can be observed that all the students in the group participated in commencing the assigned task at $4.25 \mathrm{pm}$ in their jigsaw break-out room. Evidence of collaborative dynamics is clear from the exchange of posts (interactions); for instance, the students worked together and shared options of the correct answers that they obtained for Tutorial 4.

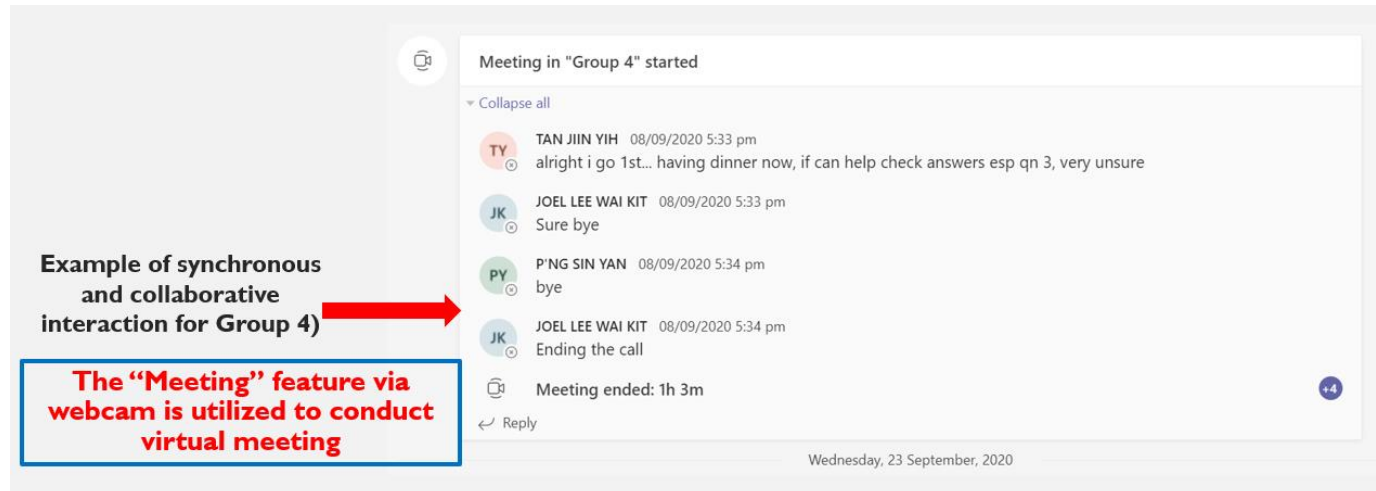

Figure 6: Virtual Meeting Through "Meet" Feature in Synchronous Jigsaw Break-out Room

Figure 6 displays the "Meet" feature via webcam utilized by the students in the jigsaw break-out room. The students in Group 4 decided to complete Tutorial 4 synchronously through a virtual meeting. They took about one hour to discuss and complete the task in Tutorial 4. It can be observed that one of the students asked to double check the answers for question 3 before submitting. The call of the virtual meeting in this jigsaw break-out room ended at around 5.34pm. 


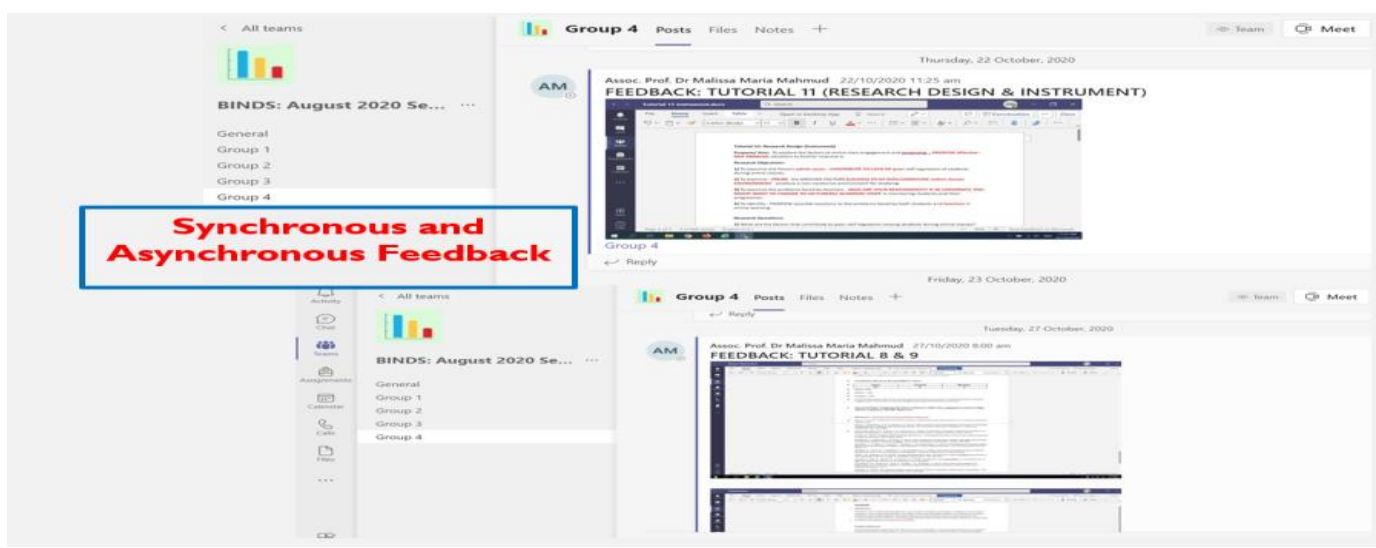

Figure 7: Synchronous and Asynchronous Feedback for Tutorial

Figure 7 shows the synchronous and asynchronous feedback provided by the teacher to the students. Each submitted tutorial by each jigsaw group was checked and marked by the teacher. Then, the marked tutorial or feedback was returned to the students through their respective jigsaw channels before the live session/class. Students could review the marked tutorial and further clarifications and discussions were done during the live class. This enhanced the understanding and fostered better interaction and engagement.

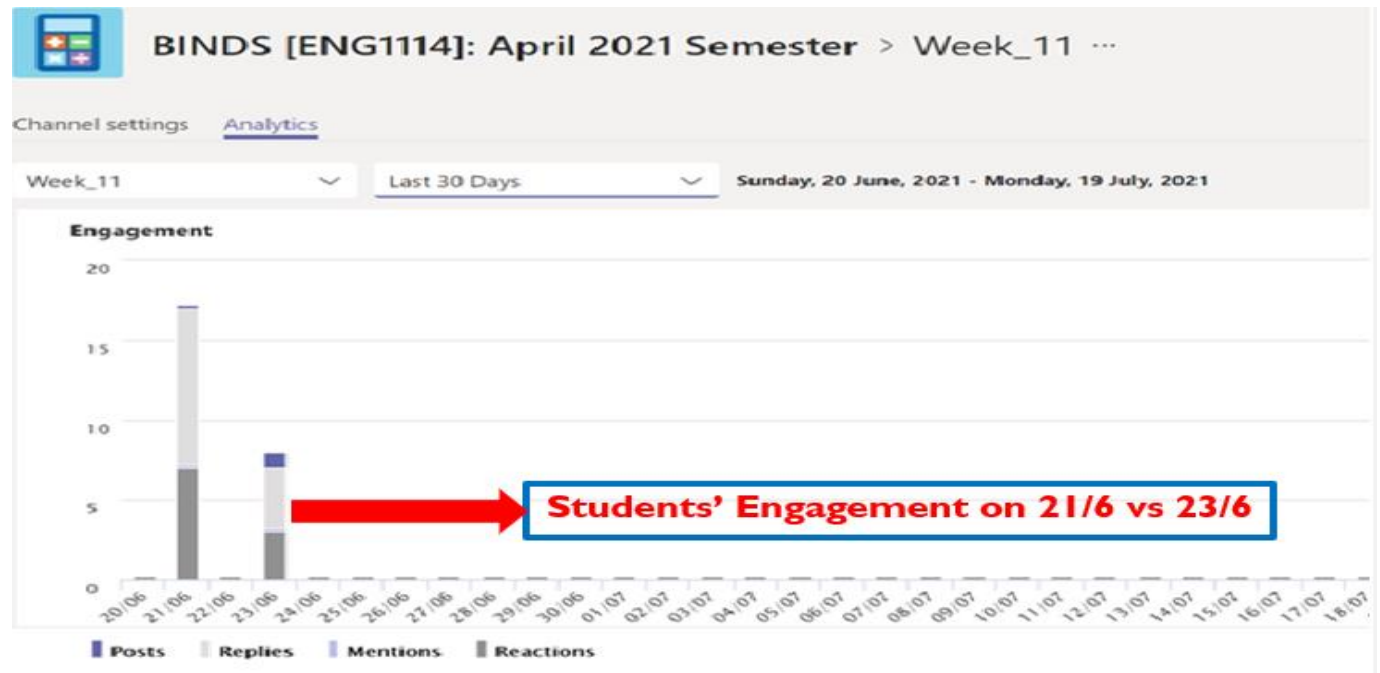

Figure 8: Students' Engagement Analysis

Figure 8 illustrates the level of engagement for the lessons conducted on 21 June as opposed to those of 23 June 2021. The learning analytics tool database was automatically updated with information from the channels. At this juncture, the frequency of logs, chats, posts, replies, mentions and reactions are used to measure the variable of engagement. It is observed that the lesson on 21 June, in which the jigsaw method was employed, yielded significantly higher engagement. Extracted data from the LMS database via the learning analytics tool would be able to offer integral information, in particular, when designing online lessons. 


\section{Discussion}

It is evident from this study that the jigsaw method in MS Teams promotes student- centred learning, allowing students to learn and perform better through stronger students engagement and collaboration. The finding is consistent with Karacop's (2017) view that cooperative learning can lead to better engagement. Baken et al. (2020) echoed a similar sentiment, namely that the utility of the jigsaw method encourages discoveries without direct facilitation and direction. Thus, students are exposed in a collaborative and active learning mode through jigsaw method, which can eventually lead to better performance and in-depth understanding of the topics at hand.

In addition, the combination of both synchronous and asynchronous jigsaw break-out rooms in this study was found to induce more interaction among the students, which led to an improved engagement. Many researchers have reported that the jigsaw method is an innovative teaching method that has a positive impact on student proactive engagement (Bhandari et al., 2017; Azmin, 2016; Earl, 2009). Compared with face-to-face teaching, few studies have shown higher knowledge retention in three to four weeks delayed post-test scores than the jigsaw method (Kumar et al., 2017; Sagsoz et al., 2017). Besides, Aronson (2000) mentioned that the jigsaw method not only efficiently convinces students to become engaged in their learning, but also allows them to learn the course content quicker through information sharing with other groups, minimizing the listening time while fostering their self-learning ability. It also maximizes the interaction among students and teacher.

This study also yielded positive outcomes on the synchronous and asynchronous interaction. It is a no-brainer that written communication can be boring and poses challenges for students to maintain their focus. In order to make online jigsaw classrooms interesting, it is important to strike a balance between the online synchronous and asynchronous mode of course delivery. For instance, in this study, the teacher or facilitator allowed the students to have one hour of online discussion within the "expert" groups and jigsaw groups, and then only continued with another 30 minutes of real-time discussion to ensure continuous momentum of interaction, especially on the assigned task. In a study conducted by Lin and Gao (2020), they found that when the students were able to connect with their peers, a sense of belonging could be prompted through the discussion and sharing of ideas in an asynchronous setting.

It is noteworthy to mention that the real-time communication using the "Meet" feature on MS Team has facilitated amplified feedback among the students during the experimental session. In this study, the designed jigsaw activity/ tasks had well- scaffolded knowledge constructions. As such, this would subsequently lead to an enjoyable learning experience (Rehman \& Fatima, 2021). Finally, it was also noticeable that feedback and rubrics provided to the students, together with the discussion and further clarification, elicited more transparent communication. When students are informed about what is expected from them, better engagement exists (Kahu et al., 2017). This is essential because merit points or peer evaluation systems, for example, then can be implemented to motivate the 
participation of the students, while reducing the non-participation and late participation which could be very common in group learning activities like the online jigsaw classroom.

\section{Conclusion and Recommendation}

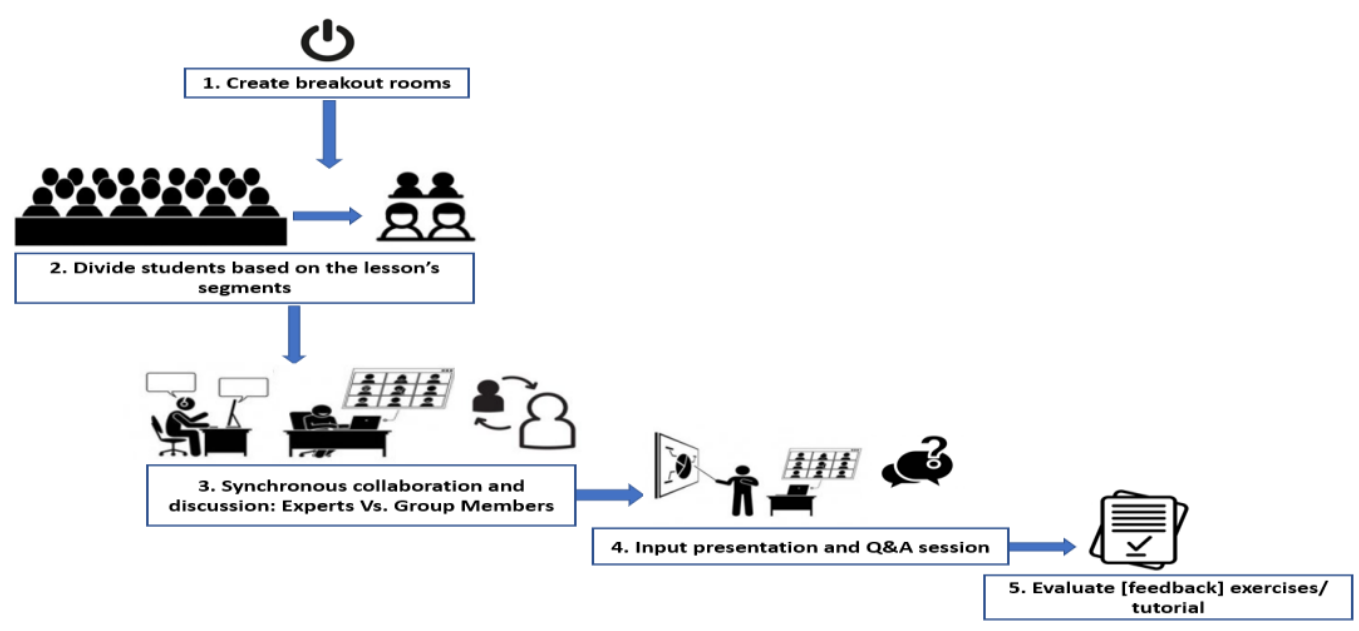

Figure 9: Proposed Design Using the Jigsaw Method Scaffolded by MS Teams

In this study, the usability and adoption of an online jigsaw method via MS Teams are presented. It is surmised that the availability of various functions and features on MS Teams, in particular the break-out room or customized channel and synchronous chat, are indicative of the likelihood to be recommended for better learning engagement and overall experience. Moreover, the significantly higher engagement frequency obtained from the learning analytics dataset suggests that the proposed design, using the jigsaw method scaffolded by MS Teams as illustrated in Figure 9, is deemed valid and scalable for wide-ranging class sizes and proficiency levels. Nonetheless, there are noticeable drawbacks in this work. Firstly, the features and functions proffered on MS Teams are not unique. In other words, there are plenty of other web-based applications with similar tools, functions and features, for example Zoom, Google Classroom and NowComment. Therefore, it is recommended for future researchers to conduct a comparative analysis among the platforms to further identify adoption and usability possibilities. The next drawback is due to the lack of a primary dataset from a survey, which could be collected at the end of each implementation. It is reckoned that a cogent understanding can be gained of what students engagement entails when the jigsaw method is deployed and survey findings are triangulated with the learning analytics dataset. Without a doubt, the use of technology in teaching and learning is here to stay. The current COVID-19 crisis is compelling the stakeholders to rethink, revamp and redesign the whole ecosystem. Likewise, it is also essential for future researchers to focus on the sustainability of learning platforms such as MS Teams to complement and support the face-to-face modalities. As such, broader user experience can be determined. 


\section{References}

$\mathrm{Ab}$ Murat, N. B. (2008). Learning through teaching and sharing in the jigsaw classroom. Annals of Dentistry University of Malaya, 15(2), 71-76.

Albó, L., Barria-Pineda, J., Brusilovsky, P. \& Hernández-Leo, D. (2019, September). Concept-level design analytics for blended courses. In European Conference on Technology Enhanced Learning (pp. 541-554). Springer, Cham.

Amador, J. A. \& Mederer, H. (2013). Migrating successful student engagement strategies online: Opportunities and challenges using jigsaw groups and problem-based learning. Journal of Online Learning and Teaching, 9(1), 89-105.

Aronson, E. (1978). The jigsaw classroom.. Revision World. https://revision world.com/search/site/Aronson\% 201978.

Aronson, E. (2000). Jigsaw classroom: Overview of the technique. Jigsaw Official Site. https://www.jigsaw-online.com

Aronson, E. (2002). Building Empathy, Compassion, and Achievement in the Jigsaw Classroom. In Improving Academic Achievement. https://doi.org/10.1016/b978012064455-1/50013-0

Azmin, N. H. (2016). Effect of the Jigsaw-Based Cooperative Learning Method on Student Performance in the General Certificate of Education Advanced-Level Psychology: An Exploratory Brunei Case Study. International Education Studies, 9(1), 91-106.

Baken, E. K., Adams, D. C. \& Rentz, M. S. (2020). Jigsaw method improves learning and retention for observation-based undergraduate biology laboratory activities. Journal of Biological Education, 1-6.

Balestrini, M., Hernández-Leo, D., Nieves, R. \& Blat, J. (2014). Technology-supported orchestration matters: Outperforming paper-based scripting in a jigsaw classroom. IEEE Transactions on Learning Technologies, 7(1). https://doi.org/10.1109/TLT.2013.33

Bhandari, B., Mehta, B., Mavai, M., Singh, Y. R. \& Singhal, A. (2017). Medical education/original article jigsaw method: An innovative way of cooperative learning in physiology. Indian J Physiol Pharmacol, 61(3), 315-321.

Bratt, C. (2008). The Jigsaw classroom under test: No effect on intergroup relations evident. Journal of Community and Applied Social Psychology, 18(5). https://doi.org/10.1002/casp.946

Casey, A. \& Fernandez-Rio, J. (2019). Cooperative Learning and the Affective Domain. Journal of Physical Education, Recreation and Dance, 90(3). https://doi.org/10.1080/07303084.2019.1559671

Chilana, P. K., Ko, A. J., Wobbrock, J. O., Grossman, T. \& Fitzmaurice, G. (2011, May). Postdeployment usability: A survey of current practices. In Proceedings of the SIGCHI Conference on Human Factors in Computing Systems (pp. 2243-2246).

Crone, T. S. \& Portillo, M. C. (2013). Jigsaw Variations and Attitudes About Learning and the Self in Cognitive Psychology. In Teaching of Psychology (Vol. 40, Issue 3). https://doi.org/10.1177/0098628313487451

Czerkawski, B. C. \& Lyman, E. W. (2016). An instructional design framework for fostering student engagement in online learning environments. TechTrends, 60(6), 532-539.

Dziuban, C., Picciano, A. G., Graham, C. R. \& Moskal, P.D. (2016). Conducting research in online and blended learning environments. New Pedagogical Frontiers. New York: Routledge, Taylor \& Francis Group.

Earl, G. L. (2009). Using cooperative learning for a drug information assignment. American journal of pharmaceutical education, 73(7).

Effendi-Hasibuan, M. H., Fuldiaratman, Dewi F., Sulistiyo, U. \& Hindarti, S. (2020). Jigsaw learning strategy in a diverse science-classroom setting: Feasibility, challenges, 
and adjustment. Cakrawala Pendidikan, 39(3). https://doi.org/10.21831/cp.v39i3.30634

Hasnine, M. N., Ahmed, M. M. H. \& Ueda, H. (2020, October). Towards Post-Pandemic Active Learning Design by connecting Strategies with Technologies. In World Conference on Mobile and Contextual Learning (pp. 101-104).

Hänze, M. \& Berger, R. (2007). Cooperative learning, motivational effects, and student characteristics: An experimental study comparing cooperative learning and direct instruction in 12th grade physics classes. Learning and Instruction, 17(1). https://doi.org/10.1016/j.learninstruc.2006.11.004

Hastie, P. \& Casey, A. (2010). Using the Jigsaw Classroom. Physical Education Matters, 5(1).

Kahu, E., Nelson, K. \& Picton, C. (2017). Student interest as a key driver of engagement for first year students. Student Success, 8(2), 55-66.

Karacop, A. (2017). The Effects of Using Jigsaw Method Based on Cooperative Learning Model in the Undergraduate Science Laboratory Practices. Universal Journal of Educational Research, 5(3), 420-434.

Kumar, V. C. S., Kalasuramath, S., Patil, S., Kumar, R. K. G., Taj, S. K. R., Jayasimha, V. L. \& Chacko, T. (2017). Effect of jigsaw co-operative learning method in improving cognitive skills among medical students. Int J Curr Microbiol, 6(3), 164-173.

Lazzari, M. (2014). Combinación de aprendizaje cooperativo e individual en una asignatura de química de materiales. Formacion Universitaria, 7(4). https:// doi.org/10.4067/S0718-50062014000400005

Lin, X. \& Gao, L. (2020). Students' Sense of Community and Perspectives of Taking Synchronous and Asynchronous Online Courses. Asian Journal of Distance Education, 15(1), 169-179.

Mahmud, M. M., Ubrani, M. B. \& Foong, W. S. (2020, January). A Meta-Analysis of Blended Learning Trends. In Proceedings of the 2020 11th International Conference on E-Education, E-Business, E-Management, and E-Learning (pp. 30-36).

Norintan, A. M. (2008). Learning through teaching and sharing in the Jigsaw Classroom. Annals of Dentistry, 15(2). https:// doi.org/10.22452/adum.vol15no2.3

Nusrath, A., Dhananjaya, S. Y., Dyavegowda, N., Arasegowda, R., Ningappa, A. \& Begum, R. (2019). Jigsaw Classroom: Is it an Effective Method of Teaching and Learning? Students' Opinions and Experience. Journal Of Clinical and Diagnostic Research. https://doi.org/10.7860/jcdr/2019/39613.12540

Preece, J., Rogers, Y. \& Sharp, H. (2007). Interaction design: Beyond human-computer interaction ( $2^{\text {nd }}$ ed.). New York, NY: John Wiley \& Sons.

Rahimi, M. \& Yadollahi, S. (2017). Effects of offline vs. online digital storytelling on the development of EFL learners' literacy skills. Cogent Education, 4(1), 1285531.

Rahmat, N. H. (2017). Exploring the use of jigsaw writing among esl writers: a classroom research. Indonesian EFL Journal, 1(2). https://doi.org/10.25134/ieflj.v1i2.621

Rehman, R. \& Fatima, S. S. (2021). An Innovation in Flipped Class Room: A teaching model to facilitate synchronous and asynchronous learning during a pandemic. Pakistan Journal of Medical Sciences, 37(1), 131.

Riggs, S. \& Linder, K. (2016). Actively engaging students in asynchronous online classes. Idea, 64, 1-10.

Sagsoz, O., Karatas, O., Turel, V., Yildiz, M. \& Kaya, E. (2017). Effectiveness of Jigsaw learning compared to lecture-based learning in dental education. European Journal of Dental Education, 21(1), 28-32.

Sopyan, F. M., Hasanah, K. U. \& Haryudin, A. (2019). Improving reading skill using jigsaw. Project (Professional Journal of English Education), 2(5). https://doi.org/10.22460/ project.v2i5.p745-751 
Stanley, J. C. (1966). The influence of Fisher's "The Design of Experiments" on educational research thirty years later. American Educational Research Journal, 3(3), 223-229.

The K. Patricia Cross Academy. (2020, June 27). Online teaching adaptation: Jigsaw [Video]. YouTube. https://www.youtube.com/watch?v=mKXY8DjtMH $\mathrm{M}$

Tsai, C. H. \& Brusilovsky, P. (2019). Exploring social recommendations with visual diversity-promoting interfaces. ACM Transactions on Interactive Intelligent Systems (TiiS), 10(1), 1-34.

Walker, I.. \& Crogan, M. (1998). Academic performance, prejudice, and the jigsaw classroom: New pieces to the puzzle. Journal of Community and Applied Social Psychology, 8(6). $\quad$ https://doi.org/10.1002/(sici)10991298(199811/12)8:6<381::aid-casp457>3.0.co;2-6

Wang, L. (2007). Sociocultural learning theories and information literacy teaching activities in higher education. Reference and User Services Quarterly, 47(2). https://doi.org/10.5860/rusq.47n2.149

Williams, D. (2004). Improving race relations in higher education: The jigsaw classroom as a missing piece to the puzzle. Urban Education, 39(3). https://doi.org/10.1177/0042085904263063 